\title{
3D-Extrusion Manufacturing of a Kaolinite Dough Taken in Its Pristine State
}

\author{
Séverine A. E. Boyer ${ }^{1 *}$, Lucie Jandet ${ }^{2}$ and Alain Burr ${ }^{1 *}$ \\ ${ }^{1}$ MINES Paris, CEMEF-Centre de Mise en Forme des Matériaux, PSL Research University, Sophia Antipolis Cedex, France, \\ ${ }^{2}$ MINES Paris Engineering School, PSL Research University, Paris Cedex, France
}

\section{OPEN ACCESS}

Edited by:

Patricia Krawczak,

IMT Lille Douai, France

Reviewed by:

David Olubiyi Obada,

Ahmadu Bello University, Nigeria Mohd Mustafa Al Bakri Abdullah,

Universiti Malaysia Perlis, Malaysia

${ }^{*}$ Correspondence:

Séverine A. E. Boyer

severine.boyer@mines-paristech.fr

Alain Burr

alain.burr@mines-paristech.fr

Specialty section:

This article was submitted to

Structural Materials,

a section of the journal

Frontiers in Materials

Received: 13 July 2020 Accepted: 10 February 2021

Published: 21 April 2021

Citation:

Boyer SAE, Jandet $L$ and Burr A (2021)

3D-Extrusion Manufacturing of a

Kaolinite Dough Taken in Its

Pristine State.

Front. Mater. 8:582885.

doi: $10.3389 /$ fmats.2021.582885
Ceramic is among the complicated materials to use in the design of fine objects. Complex shapes without any major defect are not easy to produce. In most of the cases, the production of ceramic parts is the results of three steps. Firstly, the "sculpture" of the raw piece by adding raw materials to lead to the final object. Secondly, the "drying" and finally the "high temperature oven-dry" of the dried raw object to transform the granular dough into a nice consistent compact material. Exploiting the special characteristics of ceramic is not only a thing of the past. Nowadays new possibilities, i.e., shapes and styles, can be offered in the use of ceramics, and especially where it concerns the application of the Additive Manufacturing (AM) concept. The combination of Computer Aided Design (CAD) to AM opens a completely new means of finding novel ways of processing final objects. By choosing to use kaolin clay without any chemical additions (or improvers) as "a model material," the ability to produce controlled structures with freedom in design by additive deposition modeling is exposed. Discussions relate to the concomitant control of the process parameters, the kaolin hydration and the complexity of printed structures. The optimization of process parameters (nozzle speed, layer thickness, wall thickness) were defined with the calibration of the material flow. Both windows adjusting water content in dough (\%wt) and imposing pressure in the tank of the 3D printer have been defined accordingly. The role of layer impression support was also found to be important. This study credits to use the state-of-the art technique (3D printing) to explore sustainable manufacturing of potteries.

Keywords: ceramics, 3D dough printing, metastable state, kaolin hydration, artistic pottery

\section{INTRODUCTION}

The three-dimensional (3D) printing is transforming the manufacturing technology space. It brings original concepts and promotes the emergence of native materials (and taken in their pristine state), such as biomaterials, within new possibilities of CAD engineering (Guvendiren et al., 2016; Bourell et al., 2017; Bose et al., 2018; Gutierrez-Heredia et al., 2018; Ngo et al., 2018; Harris et al., 2019; Jovic et al., 2019; Wasti and Adhikari, 2020). As example, Bose et al., in 2018 classified selected Addititive Manufacturing (AM) (binder jetting, direct energy deposition techniques, material extrusion and jetting, powder bed fusion and vat polymerization) and presented some combination of AM and biomaterials (ceramics, metallic biomaterials, polymers) to finally focus on applications of AM in biomaterials and biomedical devices (metallic implants to improve osteointegration, hard tissue engineering, soft tissue engineering). Gutierrez-Heredia et al., in 2018 presented a method for 
printing 3D models of coral colonies; they generated accurate 3D models suitable for research and education. Ngo et al., in 2018 discussed the revolutionary applications of AM (fused deposition modelling, powder bed fusion, inkjet printing, and contour crafting, stereolithography, direct energy deposition, laminated object manufacturing) in trending applications, i.e. biomedical, aerospace, buildings and protective structures. Materials of survey were metal alloys, polymer composites, ceramics, and concrete. They identified few drawbacks as defaults (voids), inferior and anisotropic microstructure and mechanical properties, divergent from design to execution, layer-by-layer appearance. Additional information can be found in the indexed work of Bourell et al., in 2017. Harris et al., in 2019 reported multimaterial 3D printing by fused filament fabrication and showed the ability of Thermoplastic PolyUrethane (TPU) to adhere to Acrylonitrile Butadiene Styrene (ABS) and acrylonitrile styrene acrylate (ASA). More recently, Jovic et al., in 2019 outlined the most widely used biomaterials derived from land plants and marine algae (nanocellulose, pectin, starch, alginate, agarose, fucoidan, and carrageenan) with an in-depth focus on nanocellulose and alginate. They discussed their potential in 3D bioprinting for tissue engineering, drug delivery, wound healing, and implantable medical devices. And Wasti and Adhikari in 2020 reviewed biomaterials (Poly-Lactid Acid (PLA), PolyHydroxy-Alkanoate (PHA) and blends used in fused deposition modeling technique.

Various ranges of applications are concerned, for instance aerospace, electronics, aeronautics, automobile, art, biomedical, healthcare (Azad et al., 2020; Fan et al., 2020), architecture, and building (Shakor et al., 2019), fashionable food industries (Godoi et al., 2016). Since the pioneer works reported in 2013, 4D printing is introduced and proposes a new strategy that involves the design of a $3 \mathrm{D}$ printed part able to undergo a controllable shape change with time as described by (Ge et al., 2013; Tibbits, 2014; González-Henríquez et al., 2019).

The Rapid Prototyping (RP) is based on the local deposition of small volumes of material to directly form as a solderlike shape. The available technologies have been improving constantly since the first French artist Willeme's photosculpture in 1860. The history and evolution of AM technologies are comprehensively discussed by Bourell et al. (Bourell et al., 2009). Among the AM technology, the concept of continuous microextrusion printing is used. The material is selectively dispensed through a nozzle over a movable platform (build stage). When using extrusion, two primary approaches are found. $i$. First, the commonly FDM (Fused Deposition Modeling) where the material is molten (heat) inside the channel of the liquefier. This step allows flow out through the nozzle and bonding before complete solidification. And $i$. second, the revisited use of a supersaturated fluid slurry, as a material for extrusion, is usually carried out without heating. The later includes pressure-assisted methods such as pneumatic (air, compressed gas) and piston methods (Godoi et al., 2016), as both presented in micro-extrusion bioprinters (Bose et al., 2018; Kumar et al., 2019).

Continuous efforts have made possible the use of geomaterials in $3 \mathrm{D}$ printing technologies. Issues, potentialities and opportunities are illustrated in works such as (Travitzky et al., 2014; Zocca et al., 2015; Gosselin et al., 2016; Zhong et al., 2017;
Buswell et al., 2018; Lin et al., 2019; Shahsavari and Hwang, 2020; Wang et al., 2020). However, progress is still needed in this geomaterials domain. Indeed, as introduced by (Nair et al., 2020; Shakor et al., 2020a; Shakor et al., 2020b), the printing procedures and dimensional accuracies of printed objects lack details. These details call for a large crossing of knowledge, i.e. interdependent factors of geo-based matrix/control of the process/functional properties.

For this reason, the present research has evaluated kaolin clays in its pristine state. Kaolinite is one of the widely used aluminosilicate minerals, encountered in the manufacturing of traditional ceramics, paper, pottery, paintings and cosmetics. Generally speaking, chemical additions (or improvers) are brought together to propose the best formulation to meet a specific clay-based material; the improvement requiring to answer diverse features as thermal and mechanical properties, rheology, inter-particle interactions, stable phase (Revelo and Colorado, 2018; Revelo and Colorado, 2019).

The regular fused deposition modeling apparatus (FDM) was adapting with a pressure-assisted piston connected to a single screw extruder before the regular nozzle used for printing thermoplastics. For a fundamental approach, the clay-water mixture was selected as a model system, without any chemical additions (or improvers). Concomitant control of the tested process parameters, the kaolin hydration and the complexity of printed structures permitted to understand the effect of the printing conditions on the green mixture. A like-pottery part was fabricated, illustrating the ability, and feasibility of this technology. Post-processed temperature curing, i.e. sintering or as called "high temperature oven-dry," validated the structural stability of the pottery.

\section{MATERIALS AND METHODS}

\section{Material Properties}

\section{Kaolin Clay and Slurries}

Kaolin clay was chosen due to its availability worldwide as minerals found in the Earth's crust, particularly in South of France with its pottery. The porcelain powder (PT010B: composition of kaolin clay $50-100 \%$ and quartz $10-25 \%$, density of $2.6 \mathrm{~g} / \mathrm{cm}^{3}$ ) was supplied by Imerys (France).

The eco-responsible character and the low cost of kaolin clays is also an important factor for scaling up and promoting the results, for individual artists to big traditional ceramics industry and specific use. The single clay was used throughout all slurries, without purification. Only the amount of water was varied from one formulation to the other to, in the end, work with a single formulation optimized for processing. Therefore, the chemical composition and the solid particle characteristics (network microstructure, size distribution and shape of particles) may be deemed as constant and practically without any effect on the final printed parts.

\section{From Atomic Composition to Hexagonal Sheets}

The crystallographic structure of kaolin is made of two layers. One is formed by octahedral meshes sharing their oxygen atoms 

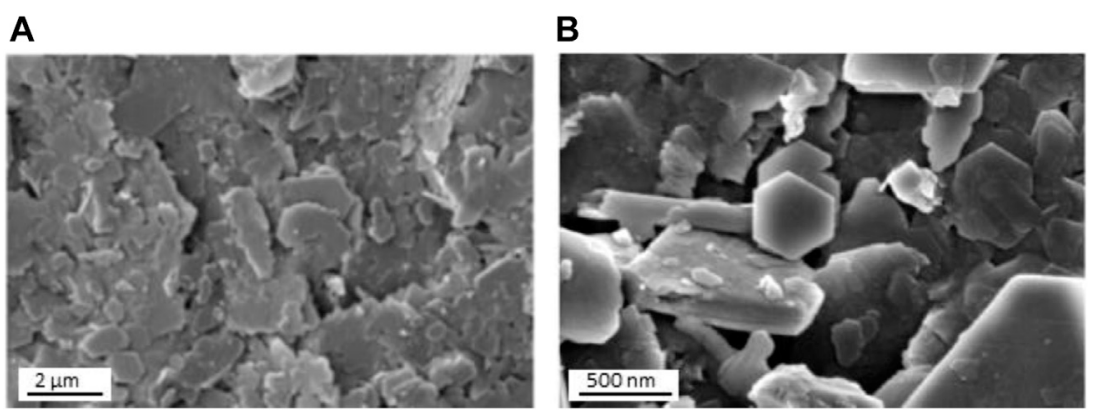

FIGURE 1 | Hexagonal booklet-like sheets of native (powder) kaolin clay (A) scale of $2 \mu \mathrm{m}$, (B) scale of $500 \mathrm{~nm}$. Hexagonal structure forms of steps which reveal successive layers of sheets.

at their corners with other neighbour octahedral meshes. The second one is an assembly of tetrahedral meshes connected to the octahedral layer with hydroxide groups. Aluminum is in the center of the octahedra and silicon in the center of the tetrahedra. Kaolinite is a widely used hydrated alumino-silicate minerals, mainly composed by kaolin clay with a theoretical molecular formula of $\mathrm{Al}_{2} \mathrm{O}_{3} 2 \mathrm{SiO}_{2} 2 \mathrm{H}_{2} \mathrm{O}$ (Bergaya et al., 2006; Loginov et al., 2008). In the observable morphology scale, the assembly of a layer formed of octahedra to a layer formed of tetrahedra forms is called a leaflet. The surfaces of these single sheets have hydroxide and oxygen atoms which allow water molecules to be inserted between the sheets (Awad et al., 2017; Awad et al., 2019). Figure 1 displays the hexagonal sheets, on native kaolin clay.

\section{Hydration}

The suspensions of kaolin clay were prepared from dry kaolinite powder. These suspensions were conducted by mechanically mixing the clay powder with water (or dispersant solution) at appropriate quantities. Water to clay ratios (in \% wt) was of 23 and $27 \%$ (see Results part). The water content was checked for each test, by collecting a certain mass of the suspensions and measuring it before and after drying at $37^{\circ} \mathrm{C}$. This temperature of $37^{\circ} \mathrm{C}$ was selected to follow the kaolin clay loss of water mass over time and to avoid any deformation of objects. For a standard consideration, recent work by Shakor et al. (Shakor et al., 2020a) post-processed the objects in an oven for $3 \mathrm{~h}$ at $60^{\circ} \mathrm{C}$.

\section{Viscosity and Filament Size}

The rheological behavior of the green slurries was directly verified with the $3 \mathrm{D}$ printer. The flow rate was determined using a capillarity test (controlled directly by the $3 \mathrm{D}$ printer). Appropriate G-code files with different "extrusion screw speed rates" were tested to perform a single linear path with the printer. The nozzle speed was varied while the nozzle diameter stayed constant $(1.0 \mathrm{~mm})$. Then a visual appreciation was made to maintain the optimal print flow. This is necessary to calibrate the throughput, which is unique to each individual printer.

The real flow and the flow programmed from a test code in which the printing time was set (and so only the flow was changed) were compared (see Results part, Figure 2). Then single line objects were printed to determine the optimal speed

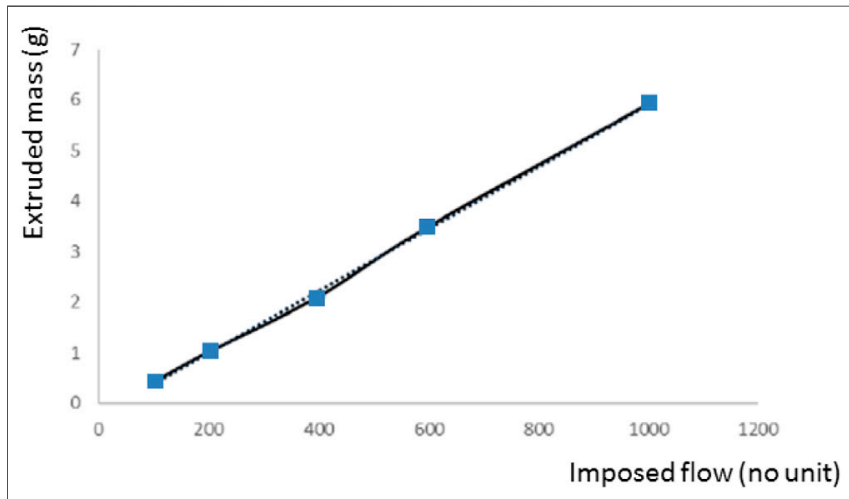

FIGURE 2 | Collected data of extruded mass with imposed flow. Flow is without unit, taken as in the hardware. It corresponds to an activation of the stepper motor of the extruder, and it is compatible with the G-code which controls it.

TABLE 1 | Key parameters in 3D printer, constant flow of $1 \mathrm{~mm} / \mathrm{s}$, nozzle diameter of $1.0 \mathrm{~mm}$.

\begin{tabular}{lcccc}
\hline $\begin{array}{l}\text { Material } \\
\text { flow }\end{array}$ & $\begin{array}{c}\text { Printing } \\
\text { speed }\end{array}$ & $\begin{array}{c}\text { Layer } \\
\text { thickness }\end{array}$ & $\begin{array}{c}\text { Wall } \\
\text { thickness }\end{array}$ & Infill \\
\hline $60 \%{ }_{-}^{a}$ & $1 \mathrm{~mm} / \mathrm{s}_{-}^{\mathrm{b}}$ & $1 \mathrm{~mm}$ & $1 \mathrm{~mm}$ & Concentric \\
\hline${ }^{\mathrm{a}}$ Proper to our software controller. & & & \\
${ }^{b}$ To be tested directly on the printer with the clay extruder. &
\end{tabular}

of the nozzle. Again a visual inspection of the surface of the filament was made to verify the homogeneity of the printed lines. A slow speed of $1 \mathrm{~mm} / \mathrm{s}$ was chosen to produce a very good surface definition of the pottery, with a thickness of $1 \mathrm{~mm}$ for all layers (see Table 1).

\section{Methodology and Approach}

As identified in the spectrum of works of (Buswell et al., 2018), the clay in all its forms is surrounded: properties of wet materials prior to solidification (i.e. pumpability and extrudability); hardened properties of $3 \mathrm{D}$ parts, achievement of geometric conformity. 


\section{Pressure-Assisted Deposition Modelling}

A commercial Delta WASP 2040 TURBO Printer (Italy) was employed to produce prints of the kaolinite parts. The Delta printer is composed of three mechanical arms powered by three independent motors. In the present work, the $3 \mathrm{D}$ printer is a modification of a regular Delta fused deposition modeling (FDM) machine in which the thermo-mechanical system for carrying out the extrusion process was adapted to the clay configuration. In clay configuration, no more temperature control is possible.

The machine extrusion unit is connected to a piston tank $(3 \mathrm{~L})$, which contains the clay dough, and a nozzle for filament layer deposition. The material is directly transported in its paste (i.e. slurries) form with a pressure-assisted piston system (2.5-3.5 bar) just before it is extruded (see Results part). The whole system works at ambient temperature (nozzle, print with tray).

The Delta printer can produce parts of $400 \mathrm{~mm}$ in height and $200 \mathrm{~mm}$ in diameter. The advantage of such a printer is its aptitude to print large parts in height unlike other printers. The minimum thickness of a layer is about $50 \mu \mathrm{m}$ and the maximum thickness is $330 \mu \mathrm{m}$. The maximum speed at which the paste can be deposited is $300 \mathrm{~mm} / \mathrm{s}$ just as the speed of moving the print head.

The modelled-parts (digital one) were scaled and orientated in an upright position. They were printed with the amount of infill for all prints set at $100 \%$, without any scaffold support material, i.e. only walls.

Printed parts were developed layer by layer at a thickness of $h$ $=1 \mathrm{~mm}$ per layer. The thickness was optimized by reporting a study with thickness variation from $0.3,0.6$ and $1.0 \mathrm{~mm}$ respectively. Simultaneously, the speed of the moving of the print head was taken to be $1 \mathrm{~mm} / \mathrm{s}$. The speed of $1 \mathrm{~mm} / \mathrm{s}$ is in adequacy with the flow speed that was used in the Gcode "capillary" test, directly on the 3D machine.

The basement orientation layers, that is, the first layers of the support surface or foundation of the modeled part, have been defined by the printer specifications (concentric or square). No effect was evidenced in the quality of the successive building layers, even if a concentric or squared foundation was chosen.

But it could and can find its importance when looking at drying, sintering and mechanical behavior.

Skin overlap was set to 1 , which indicates full overlap between the outer perimeter and the infill.

To ensure good adhesions of the first deposit layer (which supports the rest of the structure), different support surfaces for impression were tested, i.e. aluminum foil, paper, and polishing paper (see Results part).

\section{Specimen Replication, Software vs. Hardware}

Each trial PAM files (gmesh, version 4.1.4) were imported into Cura $3 \mathrm{D}$, an open source slicing software for $3 \mathrm{D}$ printers (version 4.4.1) to generate the individual printing slices, paths, or patterns (software). These slices were then compiled and exported as a G-code file ready to be printed on the printer. The file transfer is made via an SD card to the printer (hardware).

\section{Thermal Stabilization, Sintering}

Selected printed parts were open-air dried at $37^{\circ} \mathrm{C}$ for $24 \mathrm{~h}$. They were then sintered in a furnace (Carbolite type, United Kingdom) at $500^{\circ} \mathrm{C}$ (campaign 1 ) or $700^{\circ} \mathrm{C}$ (campaign 2$)$ for $1 \mathrm{~h}$, and then at $1,200^{\circ} \mathrm{C}$ for $1 \mathrm{~h}$, respectively in air atmosphere. The conditions were selected by following a pottery process and to control the evolution of the metastable states encountered in clay. The heating and cooling temperature ramps were $10^{\circ} \mathrm{C} / \mathrm{min}$.

\section{Structural Characterization and Mechanical Tests \\ Nano-Micro-Meso-Scales Structure}

The morphology of nano-micro scales structure was evaluated for the raw and in-transition materials. Scanning Electron Microscopy with a high resolution Field Emission in high vacuum mode (MAIA3 Triglav FESEM, TESCAN type, Czech Republic) was used. Samples were mounted on carbon tape and coated with a $7 \mathrm{~nm}$ platinum film controlled by a quart crystal nano-balance using a Quorum Q150TES to $30 \mathrm{~mA} \mathrm{AC}$. The meso-scale structure was characterized with a binocular microscope (Olympus SZH10, Japan) and an optical microscope (Olympus PMG3, Japan) in reflexion mode.

\section{Compression}

Bulk compression test on sintered parts were performed at $1 \mathrm{~mm} /$ min, total deformation of $25 \%$, at $23^{\circ} \mathrm{C}$ (Dartec HA250 type, United States).

\section{Hardness}

Bulk hardness was tested using a single lap joint specimen (on a sanded surface of sintered parts), by Knoop indentation tests done for $10 \mathrm{~s}$ in force loading $1 \mathrm{Kgf}$, at $23^{\circ} \mathrm{C}$ (Buehler type, Switzerland) (Ghorbal et al., 2017).

\section{RESULTS AND DISCUSSIONS}

To ensure reproducibility, a methodology has been developed. Itemized protocols concern first the slurries and second the adaptation of the thermoplastic $3 \mathrm{D}$ printer to clay configuration.

\section{Slurries \\ Hydration}

In this step, our g-code calibration test maintains two process parameters constant: the flow of $1 \mathrm{~mm} / \mathrm{s}$ and the nozzle diameter of $1.0 \mathrm{~mm}$. Different hydration \%, in $\mathrm{H}_{2} \mathrm{O}$ wt, have been tested. The conditions to allow the identification of as named "good printing" slurries are summarized in Table 2. The filament diameter and the collapse between filaments were checked post process after the g-code calibration test. The viscosity can play an important role in ensuring defect-free products (Chan et al., 2020). The best solution of the g-code test depends on the conjunction with a suitable combination of printing pressures and speeds. Indeed, at first kaolinite dough should present viscoelastic characteristic to allow extrusion through the fine 
TABLE 2 | Percentage of water in printing paste, constant flow of $1 \mathrm{~mm} / \mathrm{s}$, nozzle diameter of $1.0 \mathrm{~mm}$.

\begin{tabular}{|c|c|c|}
\hline Water, \%wt & Aspect with illustration & Consequence \\
\hline$<23$ & Too solid & $\begin{array}{l}\text {-Poor merger between filaments } \\
\text {-Irregular flow }\end{array}$ \\
\hline $24.5-26$ & Fine line between too solid-too fluid & $\begin{array}{l}\text {-Good performance of the piece } \\
\text {-Homogeneous filaments } \\
\text {-Regular flow }\end{array}$ \\
\hline$>27$ & Too fluid & $\begin{array}{l}\text {-Bad behavior of the printed part (slumping) } \\
\text {-Non-homogeneous filaments } \\
\text {-No regular flow, in the form of drops }\end{array}$ \\
\hline
\end{tabular}

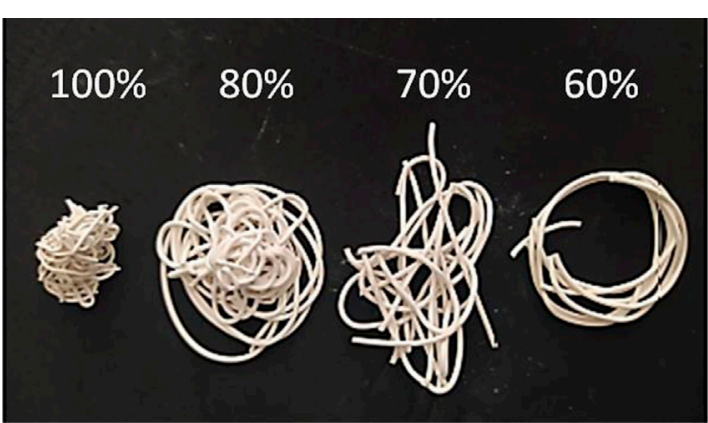

FIGURE 3 | Shear-thinning kaolinite dough suspension behaviors, for highest to lowest speed (\%).

nozzle, and then turn into self-supporting clay prior postdeposition of the consecutive layers.

\section{Nonplastic Dry Kaolin Clay}

As water is added, the kaolin clay becomes plastic (Table 2A). The water $\left(<27 \%\right.$ wt $\left.\mathrm{H}_{2} \mathrm{O}\right)$ acts as a lubricant, surrounding the clay platelets and allowing them to glide over each other. Surface tension forces acting both on the water and the clay bind them weakly together and allow a printed object to retain its shape (24.5-26\%wt $\mathrm{H}_{2} \mathrm{O}$ ) (Table 2B). The diameter of filament of kaolinite dough (950 $\mu \mathrm{m}$ checked) respected the nozzle one $(1.0 \mathrm{~mm})$. When excess water is added $\left(>27 \%\right.$ wt $\left.\mathrm{H}_{2} \mathrm{O}\right)$, more than the needed minimum to maintain surface tension, water and mass will start to flow (Table 2C). Kaolin clay becomes too fluid to retain the original shape of the object as it was formed from the CAD part.
The development of plasticity in clay is critical to the manufacture of ceramics. Depending on the composition of the clay, plasticity will develop over a narrow range of water content. The hydration window for processing is identified between 24.5 and $26 \%$ wt $\mathrm{H}_{2} \mathrm{O}$; that shows all the importance in preparing valuable slurries.

\section{Real Flow Rate}

In our g-code calibration the flow is saying constant. The flow rate is set on the Cura software as a percentage. It is per default equal to $100 \%$. Data translation between software to hardware jobs needed to make a correction of $60 \%$ in hardware flow rate. The average extruder mass as a function of the programmed flow rate was then checked, as collected in Figure 2. The real flow and the programmed flow are perfectly equivalent. The correlation coefficient of 0.999 allows us to validate the adaptation of the throughput in hardware when it is modified in software.

In addition, it can be visually noticed (Figure 3 ) that for the same movement speed, the flow rate changes the behavior of the kaolinite dough: the higher its speed, the less viscous the fluid. In fact, the supersaturated suspensions of kaolin clay display a shearthinning (non-Newtonian thixotropic) behaviour (Coussot, 1995; Loginov et al., 2008; Ordonez et al., 2019). The difference in viscosity behavior gives evidence that suspensions of kaolin clay can flow much easier during a print. Thus, the flow of the slurries does not depend merely on its water content but also on the printing speed, and temperature around. This behavior would allow kaolin clay to settle more easily into the $\mathrm{n}$ - 1 layer, meaning that the cold adhesion would be inherently stronger. The addition of water to raw kaolinite produces a plastic mixture which can be 
TABLE 3 | Tank inlet pressure adjustment, constant flow of $1 \mathrm{~mm} / \mathrm{s}$, nozzle diameter of $1.0 \mathrm{~mm}$.

\begin{tabular}{|c|c|c|}
\hline Pressure, bar & Water content, \%wt & Consequence \\
\hline$<2.5$ & $24.5-26$ & -No dough flow even when an impression is launched (clogging) \\
\hline $2.5-3.5$ & $24.5-26$ & -Good flow, dough only came out when the print is launched, setting validated \\
\hline$>3.5$ & $24.5-26$ & -Dough flowed alone, without the printing being launched \\
\hline
\end{tabular}

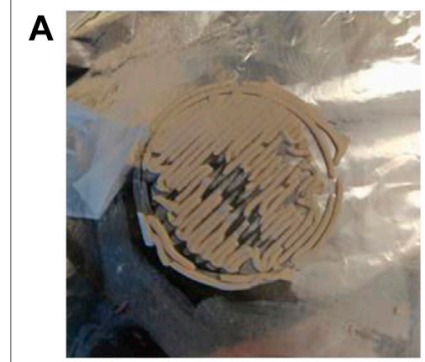

B

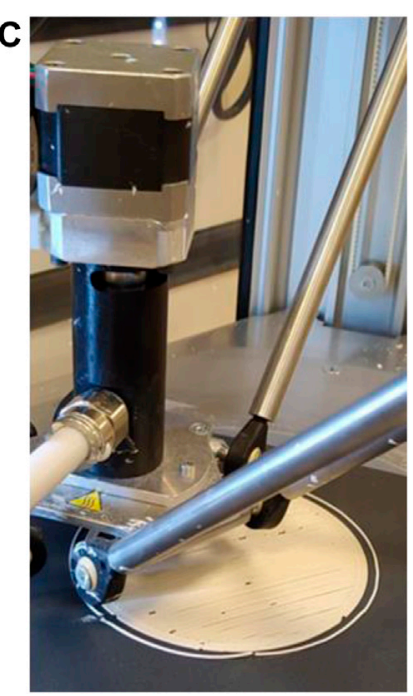

FIGURE 4 | First layer of a cylinder printing of kaolinite dough with different substrates (A) aluminium, (B) paper, and (C) polishing paper (mesh size P320).

shaped without rupture. Kaolinite exhibits plastic properties for primary reasons: kaolin clay particles themselves are crystalline platelet-like structure; with small size of particles; and the presence of water called "water of formation" between the crystalline clay particles. The water acts as a lubricant and allows the clay particles to slide across each other rather than rupture when a shear force is applied.

\section{Adaptation of Thermoplastic 3D Printer to Clay Configuration}

\section{The Effect of Print Order on Pressure}

Two parameters are used to modify the print throughput: the throughput imposed by the software and the pressure imposed in the pressurized tank. To have a total control of the flow, a window for adjusting the imposed pressure in the tank was kept constant, $(<2.5 ; 2.5-3.5$, and $>3.5)$ bar, only the software parameter has been changed. It was possible then to fix the following pressure window as given in Table 3 , the data are collected on the optimized water content given in Table 2 .

\section{The Effect of Print Order on First Layer Impression Support}

The very first layer was printed and only the optimal condition was tested (24.5-26 wt $\% \mathrm{H}_{2} \mathrm{O}$, nozzle diameter of $1.0 \mathrm{~mm}$, nozzle speed of $1 \mathrm{~mm} / \mathrm{s}$, software rate $100 \%(60 \%$ in hardware), thickness layer $1 \mathrm{~mm}$, skin overlap set at 1 ). Figure 4 illustrates the first layer (foundation) of a cylinder printing of kaolin clay with different substrates A aluminium, B paper, and C polishing paper (mesh size P320, which corresponds to a grain size of $46.2 \mu \mathrm{m}$ ). Aluminum adhesion is the worst; the material slides over the surface and gives heterogeneous dimensional control. For the paper, the adhesion in the early stages of printing is correct, but after a while the adhesion becomes of poor quality. In fact, it has been observed that the surface of the paper does not stay dry but absorbs water (moisture) from the slurry of kaolinite; the surface curls. The best compromise is found for the polishing paper (P320 mesh size). It is mainly due to the surface roughness and probably to its impermeable surface or poor water absorbing character, giving a better anchorage to the deposited material. A P1200 mesh size (equivalent to $15.3 \mu \mathrm{m}$ ) was also tested and did not give better adhesion. Generally speaking, on one hand, the adhesion must be sufficient to allow the slurries to follow the required printing conditions. On the other hand, the adhesion must leave certain freedom to the layer of slurries to avoid any cracking as the slurries start to dry during printing. Indeed, once printed, water can evaporate freely and the slurries will contract (see To Access to the Effect of Print Order on Structural 3D Making and Sintering).

\section{To Access to the Effect of Print Order on Structural 3D Making and Sintering}

Kaolin needs post "high temperature oven-dry" treatment to produce solid ceramic objects. This additional processing should be carefully checked and carried out to prevent further defects in the part such as its explosion or change of dimension during sintering (such as an unwanted deformation) and to ensure controlled phase change of the hydrated kaolin (Njoya et al., 2017). The sintering profile is illustrated in Figure 5A with morphology in Figure 5B. The chemical changes can be summarized as here after:

Step 1: heating ramps $10^{\circ} \mathrm{C} / \mathrm{min}$

Step 2: annealing $500^{\circ} \mathrm{C}$ (or $700^{\circ} \mathrm{C}$ ), $1 \mathrm{~h}$

$\mathrm{Al}_{2}(\mathrm{OH})_{4} \mathrm{Si}_{2} \mathrm{O} \rightarrow \mathrm{Al}_{2} \mathrm{O}_{3} 2 \mathrm{SiO}_{2}+2 \mathrm{H}_{2} \mathrm{O}$

(hydrated kaolin) (metakaolin) (water)

Step 3: heating ramps $10^{\circ} \mathrm{C} / \mathrm{min}$

$350-750^{\circ} \mathrm{C}, \mathrm{Al}_{2} \mathrm{O}_{3} 2 \mathrm{SiO}_{2} \rightarrow \mathrm{Al}_{2} \mathrm{O}_{3}+\mathrm{SiO}_{2}$ (metakaolin) (alumina) (silica)

950- $1050^{\circ} \mathrm{C}, \mathrm{Al}_{2} \mathrm{O}_{3} 2 \mathrm{SiO}_{2} \rightarrow \mathrm{MgAl}_{2} \mathrm{O}_{4}+\mathrm{SiO}_{2}$ (metakaolin) (spinel) (amorphous silica)

Step 4: annealing $1200^{\circ} \mathrm{C}, 1 \mathrm{~h}$

$\mathrm{Al}_{2} \mathrm{O}_{3} 2 \mathrm{SiO}_{2} \rightarrow 2\left(3 \mathrm{Al}_{2} \mathrm{O}_{3} 2 \mathrm{SiO}_{2}\right)+5 \mathrm{SiO}_{2}$

(metakaolin) (mullite) (amorphous silica)

Step 5: cooling ramp $10^{\circ} \mathrm{C} / \mathrm{min}$ 


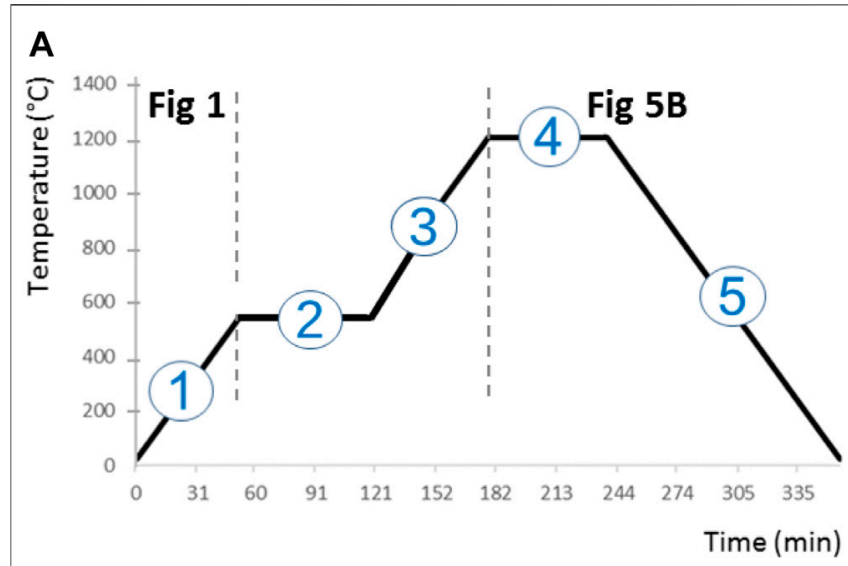

B

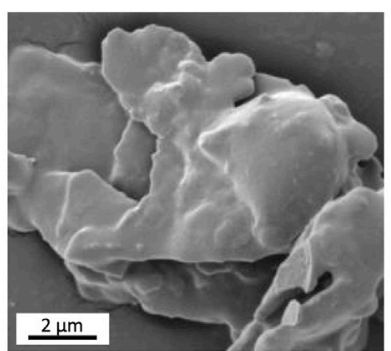

FIGURE 5 | From hydrated kaolin to pseudo-ceramic: (A) thermal history, (B) morphology after thermal sintering. Depending of the nature of the system, variety of higher temperature mineral phases may crystallize.

\section{Chemical Reaction-Scale}

Before sintering process of ceramics, the first stage is the "air drying" (Figure 5A). It is generally carried out at temperature around $150^{\circ} \mathrm{C}$, but in our case $24 \mathrm{~h}$ at $37^{\circ} \mathrm{C}$ (see Material part, Material Properties). At this stage of "air drying," the water is in the form of films surrounding the kaolin sheets; the mechanically admixed water is lost. The kaolin mixture shrinks and loses its plasticity. The solid to solid transition gives specific results, here the kaolin sheets draw closer together, until they may eventually come into contact and start to adhere. The next water loss takes place more slowly, coming from the pore spaces between the clay particles. Induced-stresses may later lead to structural damage (cracking or warping) of the printed part. The printed layers experience maximum shrinkage while exhibiting maximum of water loss. Water first evaporates from the surface of the printed part, then by capillary action, water rises from the interior to the surface and in turn evaporates. One can notice that this property makes clay a candidate for environmental remediation applications (Garrisson, 2016; Awad et al., 2019).

When the temperature rises to $200-400^{\circ} \mathrm{C}(1)$, any mechanically bound or interstitial water, still present after the ambient drying, is vaporized and driven off.

In addition to water, as the temperature rises to over $200^{\circ} \mathrm{C}$, any carbon or organic matter in the clay will start to oxidize, migrate to the surface and finally escape as $\mathrm{CO}$ or $\mathrm{CO}_{2}$. The oxidation rate and completeness depend on the temperature scan (rate), the time hold at the maximum annealing temperature, the size (wall width) of the parts, the clay and paste nature.
Two plateaus then follow the "air drying" stage. Indeed, when the clay is sintering at temperatures over $600^{\circ} \mathrm{C}$ (2), and in particular at higher temperatures of $\sim 1,200^{\circ} \mathrm{C}$ (4), the clay undergoes major structural and chemical changes due to dehydroxylation (i.e. hydroxyl ions $\left(\mathrm{OH}^{-}\right)$lost which are chemically bound within the clay lattice) (Johnson and Kessler, 1969). Chemically bound water is lost. These changes dictate the conversion of clay into a useful ceramic. High temperatures dislodge ions from original positions held in the clay structure into more favorable sites, thus converting the clay into chemically stable and structurally stronger material.

Plateau at $450-500^{\circ} \mathrm{C}(2)$ permits a complete evaporation of the water contained between the sheets of the kaolin structure. The water loss occurs abruptly during the structural transformation of hydrated kaolin to metakaolin with minor shrinkage but with increased porosity. Heating kaolinite above about $500^{\circ} \mathrm{C}$ results in a disordered crystalline form which is still reversible by rehydration back to its ordered kaolin structure. At $550^{\circ} \mathrm{C}$, the organic matter is fully oxidized. At $750-850^{\circ} \mathrm{C}$ (3), mineral water was successfully expelled from the clay. Clay starts to lose its characteristic crystalline structure, the crystal lattice itself will break down. At $950-1,100^{\circ} \mathrm{C}$, the structure of kaolin is irreversibly lost, but some illite may persist. With the breakdown in clays, high-temperature alteration and reaction products can appear, generally accompanied by pronounced shrinkage. Si-Al kaolin chain collapses on sintering into metakaolin, followed by the rejection of amorphous $\mathrm{SiO}_{2}$ during spinel formation. Above $1,000^{\circ} \mathrm{C}(4)$, high temperature new mineral mullite phase $\left(3 \mathrm{Al}_{2} \mathrm{O}_{3} 2 \mathrm{SiO}_{2}\right)$ is expected to form (Yamuna et al., 2002); $>1,100^{\circ} \mathrm{C}$ is the glassy phase of the ceramic where porosity diminishes rapidly. Notice that starting about $600^{\circ} \mathrm{C}$, vitrification or "sintering" can start in the more fusible impurities. At the plateau of $1,200^{\circ} \mathrm{C}$, the microstructural arrangements take place during the processing transformation of kaolin to ceramics. In theory, the piece should be cooked over $1,400^{\circ} \mathrm{C}$ to be completely transformed, but we only had at our disposal an oven reaching $1,200^{\circ} \mathrm{C}$ (Revelo and Colorado, 2018).

\section{Morphology-Scale}

Morphology of kaolin particles after sintering at $1,200^{\circ} \mathrm{C}$ for $1 \mathrm{~h}$ is illustrated in Figure 5B. Compared to the morphology of native kaolin (Figure 1), the hexagonal shapes have given way to more rounded shapes with a densification (Figure 5B). The densification would be done by two mechanisms, the volume distribution or/and the grain boundaries diffusion (Johnson, 1969). At this stage (it is not the scope of the works to discuss the processus that will require further analysis) diffusion in volume therefore in the solid state is a time dependent processus sensitive to the sintering speed. Secondly, the diffusion at interfaces (grain boundaries) would be plausible since observations with Scanning Electron Microscopy shows that the pseudo-hexagonal plate structure seems to be retained during densification and after transformation of metakaolin. This morphology as well as small size (about $2 \mu \mathrm{m}$ ) would favor obtaining a large specific surface of solid-solid contacts necessary for efficient diffusion at grain boundaries. It is also necessary to consider the simultaneous existence of a mechanism of densification by viscous flux which has been demonstrated in the literature during the sintering of compacts or kaolinite-based 

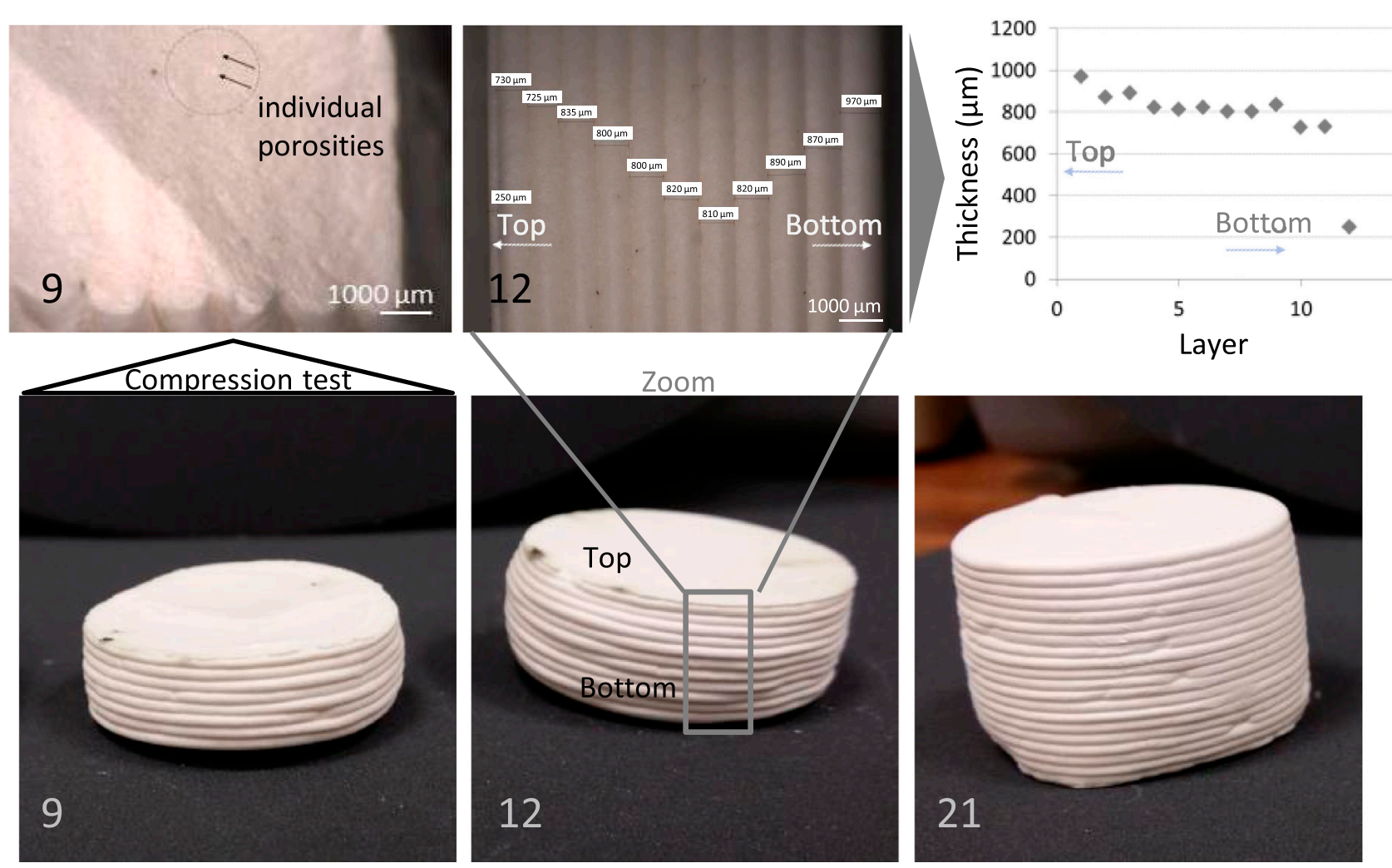

FIGURE 6 | Printed pawns after sintering, first campaign with Step 2: annealing at $500^{\circ} \mathrm{C}, 1 \mathrm{~h}$. The illustrations ( 9 , 12 , and $\left.21 \mathrm{~mm}\right)$ show the dimensional stability of the parts. Right side: facies of rupture after compression test ( $1 \mathrm{~mm} / \mathrm{min} 25 \%$ deformation, $\mathrm{T} 23^{\circ} \mathrm{C}$ ) on $9 \mathrm{~mm}$ pawn. Medium side: size of the inter-filament on $12 \mathrm{~mm}$ pawn. Printed-layer thickness of $1 \mathrm{~mm}$. Cylinders of $20 \mathrm{~mm}$ in diameter.

ceramics (Cambier et al., 1984). This point considers additional open questions, the application of the speed method, the constant annealing, the growth of primary mullite above $1,150^{\circ} \mathrm{C}$ and, but around $1,250^{\circ} \mathrm{C}$ the crystallization of new phases (cristobalite and secondary mullite).

\section{D Printed Part-Scale}

Printed pawns of different size $(3,9,12,15,18$, and $21 \mathrm{~mm}$ corresponding to the superposition of the number of layers) after sintering were observed. Bearing at Step 2: $500^{\circ}$ C(2) (campaign 1) was of interest because the pawns did not break during sintering, whatever their size, with dimension stability and conformity. Figure 6 shows 9, 12, 21-layered pieces fabricated using kaolin clay, after the first sintering campaign. The inter-layers coexist with one another much more smoothly than the top adhesion layer does (Figure 6, 12-pawn Top and Bottom and graph), thickness variation $970-730 \mu \mathrm{m}$. The layer on the top adhesion is flush, thickness of $250 \mu \mathrm{m}$.

While observing the pawns, their difference to the touch clearly shows that the microstructural arrangement expected during baking has taken place, even with a color change from beige to light pink. The kaolin is then supposed to be found in a frozen metakaolin-mullite transient state (Figure 5B).

To examine the dimensional stability idea more closely, optical microscopy was used to look at the cross-section of a rupture facies of a pawn after a compression test $(1 \mathrm{~mm} / \mathrm{min}, 25 \%$ deformation, $23^{\circ} \mathrm{C}$ ) (Figure 6, 9-facies of rupture). The facies of rupture revealed that kaolin clay indeed well settled, in the bulk and outer shell. The interlayer connection shows no defaults, only few small individual porosities are found within layer thickness itself. The hardness of the bulk material has been checked, by indentation Knoop test $\left(10^{\circ} \mathrm{s}\right.$ in force loading $\left.1 \mathrm{Kgf}, 23^{\circ} \mathrm{C}\right)$; a $\mathrm{HK}$ of [300-350] was revealed, typical values for hard materials. Enough vitrification has taken place to give a moderate degree of hardness, the clay is considered baked.

Nota, a second sintering campaign, with a Step 2: annealing at $700^{\circ} \mathrm{C}(2), 1 \mathrm{~h}$ was also experimented. This second campaign confirmed that the first level annealing step at $500^{\circ} \mathrm{C}$ is essential to allow the water to fully evaporate. At $700^{\circ} \mathrm{C}$, some water would still be confined and blocked before processing the kaolin. The pressure exerted by the water during heating would cause the fissuration or even the explosion of the object with temperature increasing. It also allowed studying the influence of the thickness of the pawn on the quality of sintering. The $3 \mathrm{~mm}$ high pawn became curled after sintering, no crack is visible showing strong inter-layer contact (Figure 7, 3-pawn). The pawns of 9, 12, 15, and $18 \mathrm{~mm}$ exhibit slight cracks. This clearly evinces concentric failure along the filament interfaces and inter-layer distortion of the outer shell (Figure 7, 18pawn Top and Bottom and graph), thickness variation range of $800-700 \mu \mathrm{m}$. The layer on the top adhesion is very flush, thickness 


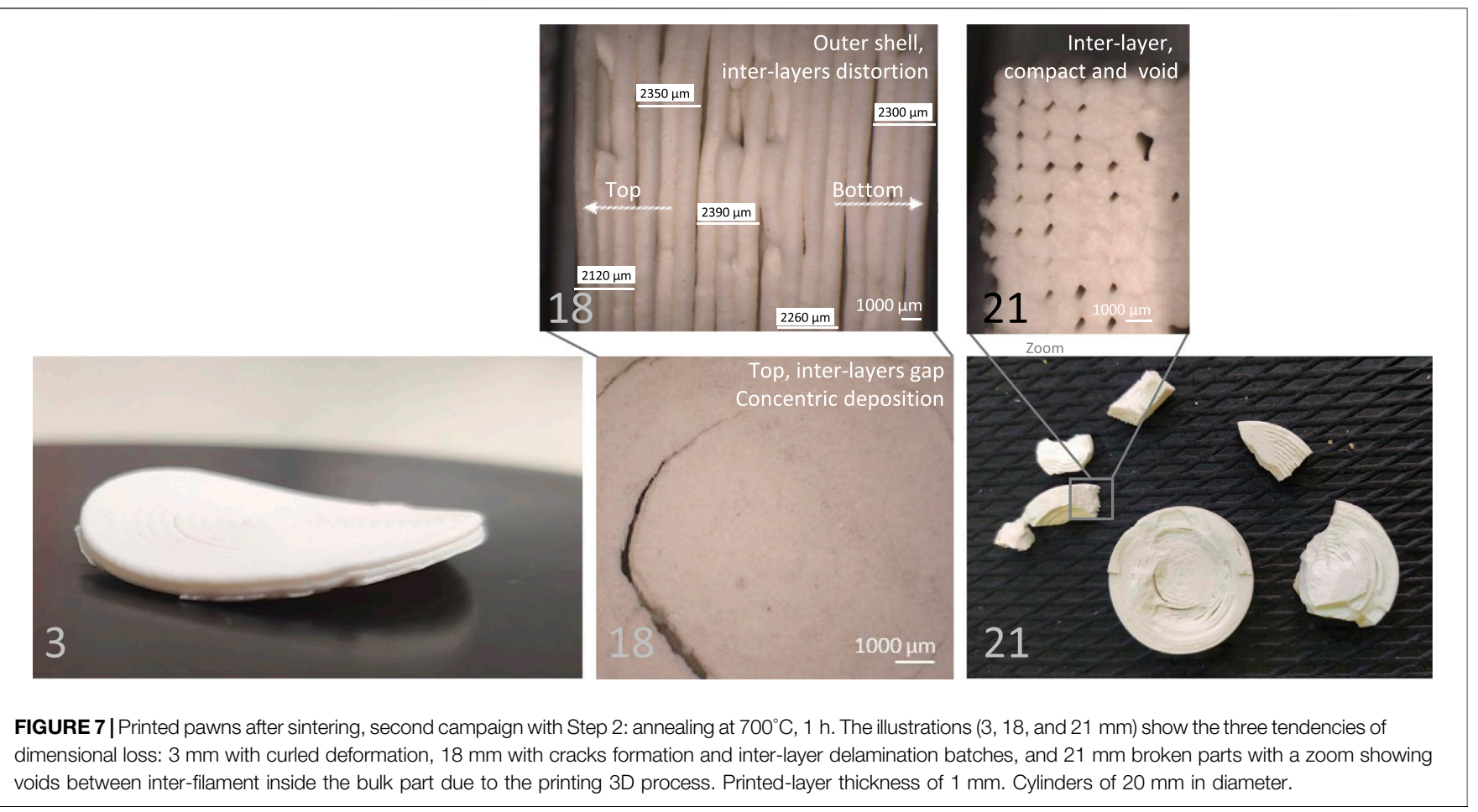

less than $250 \mu \mathrm{m}$. We can speak about anisotropic shrinkage considering that the border effect or inter-layer discontinuity makes these areas the weakest points of the printed paste, where local constraints are concentrated while water evaporates. The thickest pawn of $21 \mathrm{~mm}$ completely exploded (Figure 7, 21-pawn and facies of rupture). The facies of rupture revealed additional weakest mesoscale points between inter-layers with rectangular sometimes accentuated air gaps in the printed-bulk; sometimes compact area. Noting that these cohesive peel failures resulted from each individual pass of the printer. Internal stresses are set up in the ceramic if it loses water too fast according to the kinetics of vitrification of the kaolin. This information is very useful. The quality of the print depends on the type of structure you want to print.

\section{A 3D-PADM CERAMIC AS A PROOF OF CONCEPT}

\section{From a CAD Idea and Using Hydrated Kaolin}

Of these observations, an artistic pottery sculpture was designed, printed, dried and sintered. The main steps of the AM process are combined in Figure 8. Step 1. Software-3D model is designed by using the specialized computer-aided gmesh (version 4.1.4) modeling software. It is digitized and sliced into a number of consecutive layers (Cura 3D version 4.4.1). Step 2. Software to Hardware-The file is subsequently converted to an appropriate format for printing and exported as a G-code file to be transferred to the PADM set up. Step 3. Optimal process parameters-the printing conditions are adjusted depending on the printing methodology, i.e. slurries, pressure, air temperature, and nozzle material flow.

\section{To an Artistic Pottery}

Step 4. 3D printing-The designed structure is processed. Step 5. Drying and sintering-The structure is dried and sintered at 500 and $1,200^{\circ} \mathrm{C}$ (campaign 1, Figure 5A, Steps 2 and 4). Successfully a pottery part was fully designed. Kaolinite of low plasticity undergoes no shrinkage upon drying, the printed sculpture did not show deformation. This method permits the fabrication of fully customized and personalized products with a geometrical complex structure in an economical manner (mostly for limited productions). It is worth mentioning that ceramics PADM offers environmental responsible implications, kaolinite slurries can be recycled before complete sintering.

\section{SUMMARY AND OUTLOOK}

Manufacturing industries are being forced to create and deliver quality products while decreasing their environmental impact. Kaolinite dough taken in its pristine state is offered to bring insight to help frame and direct future research around the technology.

Specifically:

- Applying PADM technology to print complex structures in geomaterials does not rely on the concentration of manufacturing processes of the product in a single step. It is associated with the synergetic combination of the states of the materials:

- properties of wet materials prior to solidification (i.e. pumpability and extrudability), i.e. the essential constituents of ceramics (design of slurries with enhanced formulation value), 


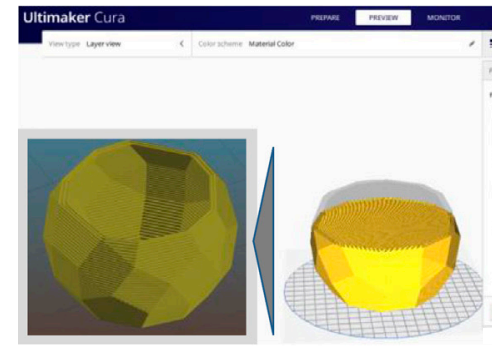

Step1. Software: to sliced-design

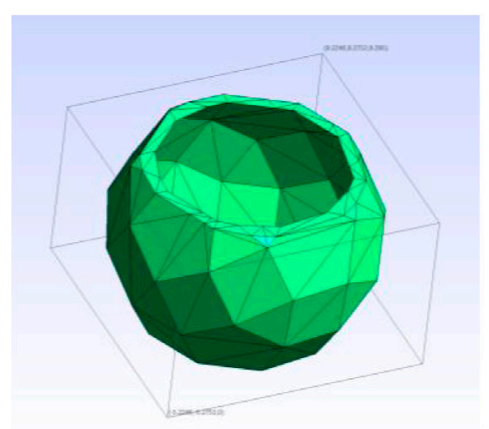

Step1. Software: from computer aided design

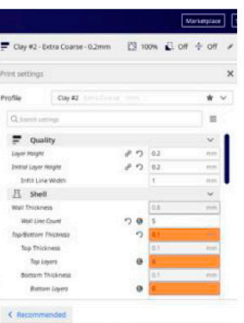

Step 2. Software to Hardware: transfert to 3D printer

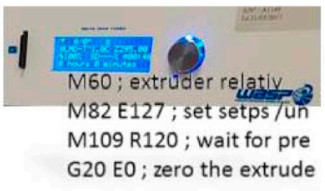

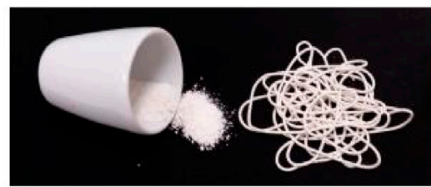

Step 3. Optimal materials $\&$ process parameters
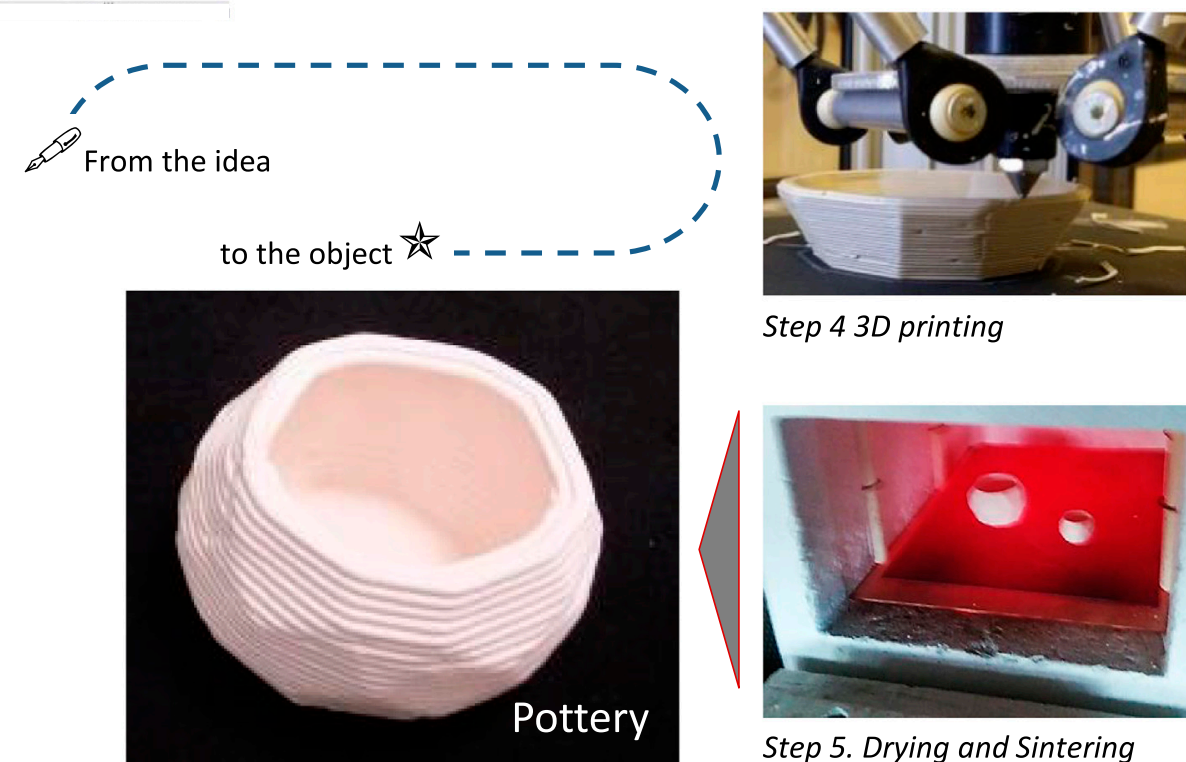

Step 4 3D printing

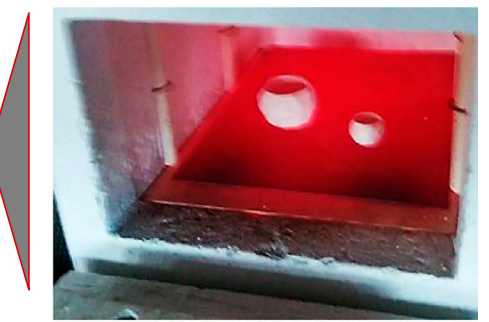

Step 5. Drying and Sintering

FIGURE 8 | From a CAD idea and using hydrated kaolinite to an artistic pottery.

- binding mechanisms and hardened properties of parts during $3 \mathrm{D}$ deposition of layers

- dehydration

- "high temperature oven-dry";

- together with the set of PADM parameters such as:

- material flow

- printing speed

- layer thickness.

- Achievement of geometric conformity is demonstrated. Ceramic parts have no cracks nor shape-instability (warping) before and after sintering.

There are still research gaps to be explored in the optimization and sustainability of AM processes. Challenges in the $3 \mathrm{D}$ printing of ceramics are not only attributed to controlling slurries properties to have sufficient workability and open time for extrusion but also the metrics to improve the precision and reliability of the manufacturing process, the efficient postprocessing structural properties e.g. strength, inter-layer adhesion, deformation, build-ability.

Finally the non-toxic and reusable materials with the development of new innovative materials are nowadays a fundamental consideration. Future works will concern the formulation of geo-materials especially applying for 3D-printing.

\section{DATA AVAILABILITY STATEMENT}

The original contributions presented in the study are included in the article/Supplementary Material, further inquiries can be directed to the corresponding authors.

\section{AUTHOR CONTRIBUTIONS}

SAEB: literature review, designing and drafting the content of the manuscript. $A B$ : reading the content of the manuscript. $L J$ with SAEB and AB: study's work.

\section{FUNDING}

Delta WASP 2040 TURBO Printer was bought through the ANR project 'Western Mediterranean Impressed Wares: An interdisciplinary research on Early Neolithic-CIMO' (ANR-14CE31-0009).

\section{ACKNOWLEDGMENTS}

The authors would like to acknowledge the MINES Paris Engineering School of PSL Research University, and especially Michel Bellet, Professor in charge of the Specialty "Materials" for 
graduate students, for giving us the nice opportunity to propose and work on this exploratory subject. The authors would also thank Suzanne Jacomet, Gilbert Fiorucci, Thierry Colin and

\section{REFERENCES}

Awad, A. M., Shaikh, S. M. R., Jalab, R., Gulied, M. H., Nasser, M. S., Benamor, A., et al. (2019). Adsorption of organic pollutants by natural and modified clays: a comprehensive review. Sep. Purif. Technol. 228, 115719-115739. doi:10.1016/j. seppur.2019.115719

Awad, M. E., López-Galindo, A., Setti, M., El-Rahmany, M. M., and Iborra, C. (2017). Kaolinite in pharmaceutics and biomedicine. Int. J. Pharm. 533 (1), 34-48. doi:10.1016/j.ijpharm.2017.09.056

Azad, M. A., Olawuni, D., Kimbell, G., Badruddoza, A. Z. M., Hossain, M. S., and Sultana, T. (2020). Polymers for extrusion-based 3D printing of pharmaceuticals: a holistic materials-process perspective. Pharmaceutics 12, 124. doi:10.3390/pharmaceutics 12020124

Bergaya, F., Theng, B. K. G., and Lagaly, G. (2006). Handbook of clay science. Amsterdam, Netherlands: Elsevier, 1572-4352.

Bose, S., Ke, D., Sahasrabudhe, H., and Bandyopadhyay, A. (2018). Additive manufacturing of biomaterials. Prog. Mater. Sci. 93, 45-111. doi:10.1016/j. pmatsci.2017.08.003

Bourell, D., Kruth, J. P., Leu, M., Levy, G., Rosen, D., Beese, A. M., et al. (2017). Materials for additive manufacturing. CIRP Ann. 66, 659-681. doi:10.1016/j. cirp.2017.05.009

Bourell, D. L., Beaman, J. J., Leu, M. C., and Rosen, D. W. (2009). “A brief history of additive manufacturing and the 2009 roadmap for additive manufacturing: looking back and looking ahead," in Proceedings of RapidTech 2009: USTurkey workshop on Rapid technologies, Istanbul, Turkey, September, 2009, 1-8

Buswell, R. A., Leal de Silva, W. R., Jones, S. Z., and Dirrenberger, J. (2018). 3D printing using concrete extrusion: a roadmap for research. Cem. Con. Res. 112, 37-49. doi:10.1016/j.cemconres.2018.05.006

Cambier, F., N'Dala, I., Deletter, M., and Anseau, M. R. (1984). Analysis of the influence of additives on the sintering of kaolinite based ceramics. Silic. Ind. 1112, 219-225.

Chan, S. S. L., Pennings, R. M., Edwards, L., and Franks, G. V. (2020). 3D printing of clay for decorative architectural applications: effect of solids volume fraction on rheology and printability. Addit. Manuf. 35, 101335-101338. doi:10.1016/j. addma.2020.101335

Coussot, P. (1995). Structural similarity and transition from Newtonian to nonNewtonian behavior for clay-water suspensions. Phys. Rev. Lett. 74 (20), 3971-3974. doi:10.1103/PhysRevLett.74.3971

Fan, D., Li, Y., Wang, X., Zhu, T., Wang, Q., Cai, H., et al. (2020). Progressive 3D printing technology and its application in medical materials. Front. Pharmacol. 11, 122. doi:10.3389/fphar.2020.00122

Garrisson, E. (2016). Techniques in archaeological geology. 2nd Edn. Berlin, Germany: Springer, 179-207.

Ge, Q., Qi, H. J., and Dunn, M. L. (2013). Active materials by four-dimension printing. Appl. Phys. Lett. 103, 131901. doi:10.1063/1.4819837

Ghorbal, G. B., Tricoteaux, A., Thuault, A., Louis, G., and Chicot, D. (2017). Comparison of conventional Knoop and Vickers hardness of ceramic materials. J. Eur. Ceram. Soc. 37 (6), 2531-2535. doi:10.1016/j.eurceramsoc.2017.02.014

Godoi, F. C., Prakash, S., and Bhandari, B. R. (2016). 3D printing technologies applied for food design: status and prospects. J. Food Eng. 179, 44-54. doi:10. 1016/j.jfoodeng.2016.01.025

González-Henríquez, C. M., Sarabia-Vallejos, M. A., and Rodriguez-Hernandez, J. (2019). Polymers for additive manufacturing and 4D-printing: materials, methodologies, and biomedical applications. Prog. Polym. Sci. 94, 57-116. doi:10.1016/j.progpolymsci.2019.03.001

Gosselin, C., Duballet, R., Roux, P., Gaudillière, N., Dirrenberger, J., and Morel, P. (2016). Large-scale 3D printing of ultra-high performance concrete-a new processing route for architects and builders. Mater. Des. 100, 102-109. doi:10. 1016/j.matdes.2016.03.097

Gutierrez-Heredia, L., Keogh, C., and Reynaud, E. G. (2018). Assessing the capabilities of additive manufacturing technologies for coral studies,
Cyrille Collin, respectively for SEM, sintering with compression, and hardness technical support. CNRS institution is also acknowledged.

education, and monitoring. Front. Mar. Sci. 5, 1-12. doi:10.3389/fmars.2018. 00278

Guvendiren, M., Molde, J., Soares, R. M., and Kohn, J. (2016). Designing biomaterials for 3D printing. ACS Biomater. Sci. Eng. 2 (10), 1679-1693. doi:10.1021/acsbiomaterials.6b00121

Harris, C. G., Jursik, N. J., Rochefort, W. E., and Walker, T. W. (2019). Additive manufacturing with soft TPU-adhesion strength in multimaterial flexible joints. Front. Mech. Eng. 5, 1-6. doi:10.3389/fmech.2019.00037

Johnson, D. L. (1969). New method of obtaining volume, grain-boundary, and surface diffusion coefficients from sintering data. J. Appl. Phys. 40 (1), 192-200. doi:10.1063/1.1657030

Johnson, H. B., and Kessler, F. (1969). Kaolinite dehydroxylation kinetics. J. Am. Ceram. Soc. 52 (4), 199-203. doi:10.1111/j.1151-2916.1969.tb13365.x

Jovic, T. H., Kungwengwe, G., Mills, A. C., and Whitaker, I. S. (2019). Plant-derived biomaterials: a review of 3D bioprinting and biomedical applications. Front. Mech. Eng. 5, 1-18. doi:10.3389/fmech.2019.00019

Kumar, A., Kargozar, S., Baino, F., and Han, S. S. (2019). Additive manufacturing methods for producing hydroxyapatite and hydroxyapatite-based composite scaffolds: a review. Front. Mater. 6, 313. doi: $10.3389 /$ fmats. 2019.00313

Lin, K., Sheikh, R., Romanazzo, S., and Roohani, I. (2019). 3D printing of bioceramic scaffolds-barriers to the clinical translation: from promise to reality, and future perspectives. Materials 12, 2660. doi:10.3390/ ma1217266010.3390/ma12172660

Loginov, M., Larue, O., Lebovka, N., and Vorobiev, E. (2008). Fluidity of highly concentrated kaolin suspensions: influence of particle concentration and presence of dispersant. Colloids Surf, A Physicochem. Eng. Asp. 325 (1-2), 64-71. doi:10.1016/j.colsurfa.2008.04.040

Nair, S. A. O., Panda, S., Santhanam, M., Sant, G., and Neithalath, N. (2020). A critical examination of the influence of material characteristics and extruder geometry on 3D printing of cementitious binders. Cem. Concr. Compos. 112 103671. doi:10.1016/j.cemconcomp.2020.103671

Ngo, T. D., Kashani, A., Imbalzano, G., Nguyen, K. T. Q., and Hui, D. (2018). Additive manufacturing (3D printing): a review of materials, methods, applications and challenges. Compos. B. Eng. 143, 172-196. doi:10.1016/j. compositesb.2018.02.012

Njoya, D., Tadjuidje, F. S., Ndzana, E. J. A., Pountouonchi, A., Tessier-Doyen, N., and Lecomte-Nana, G. (2017). Effect of flux content and heating rate on the microstructure and technological properties of Mayouom (WesternCameroon) kaolinite clay based ceramics. J. Asian Ceram. Soc. 5 (4), 422-426. doi:10.1016/j.jascer.2017.09.004

Ordoñez, E., Gallego, J. M., and Colorado, H. A. (2019). 3D printing via the direct ink writing technique of ceramic pastes from typical formulations used in traditional ceramics industry. Appl. Clay Sci. 182, 105285. doi:10.1016/j.clay. 2019.105285

Revelo, C., and Colorado, H. (2019). 3D printing of kaolinite clay with small additions of lime, fly ash and talc ceramic powders. Process. Appl. Ceram. 13 (3), 287-299. doi:10.2298/PAC1903287R

Revelo, C. F., and Colorado, H. A. (2018). 3D printing of kaolinite clay ceramics using the Direct Ink Writing (DIW) technique. Ceramics Int. 44 (5), 5673-5682. doi:10.1016/j.ceramint.2017.12.219

Shahsavari, R., and Hwang, S. H. (2020). Bioinspired cementitious materials: main strategies, progress, and applications. Front. Mater. 7, 1-12. doi:10.3389/fmats. 2020.00062

Shakor, P., Nejadi, S., and Paul, G. (2020a). Investigation into the effect of delays between printed layers on the mechanical strength of inkjet 3DP mortar. Manuf. Lett. 23, 19-22. doi:10.1016/j.mfglet.2019.11.004

Shakor, P., Nejadi, S., Paul, G., and Malek, S. (2019). Review of emerging additive manufacturing technologies in $3 \mathrm{D}$ printing of cementitious materials in the construction industry. Front. Built Environ. 4, 85. doi:10.3389/fbuil.2018. 00085

Shakor, P., Nejadi, S., Paul, G., and Sanjayan, J. (2020b). Dimensional accuracy, flowability, wettability, and porosity in inkjet 3DP for gypsum and cement 
mortar materials. Autom. Constr. 110, 102964. doi:10.1016/j.autcon.2019. 102964

Tibbits, S. (2014). 4D printing: multi-material shape change. Archit Des. 84, 116-121. doi:10.1002/ad.1710

Travitzky, N., Bonet, A., Dermeik, B., Fey, T., Filbert-Demut, I., Schlier, L., et al. (2014). Additive manufacturing of ceramic-based materials. Adv. Eng. Mater. 16 (6), 729-754. doi:10.1002/adem.201400097

Wang, Z., Yuan, X., Yang, J., Haun, Y., Gao, X., Li, Z., et al. (2020). 3D-printed flexible, Ag-coated PNN-PZT ceramic-polymer grid-composite for electromechanical energy conversion. Nano Energy 73, 104737. doi:10.1016/ j.nanoen.2020.104737

Wasti, S., and Adhikari, S. (2020). Use of biomaterials for 3D printing by fused deposition modeling technique: a review. Front. Chem. 8, 315. doi:10.3389/ fchem.2020.00315

Yamuna, A., Devanarayanan, S., and Lalithambika, M. (2002). Phase-pure mullite from kaolinite. J. Am. Ceram. Soc. 85 (6), 1409-1413. doi:10.1111/j.1151-2916. 2002.tb00289.x
Zhong, G., Vaezi, M., Liu, P., Pan, L., and Yang, S. (2017). Characterization approach on the extrusion process of bioceramics for the $3 \mathrm{D}$ printing of bone tissue engineering scaffolds. Ceramics Int. 43 (16), 13860-13868. doi:10.1016/j.ceramint.2017.07.109

Zocca, A., Colombo, P., Gomes, C. M., and Günster, J. (2015). Additive manufacturing of ceramics: issues, potentialities, and opportunities. J. Am. Ceram. Soc. 98 (7), 1983-2001. doi:10.1111/jace.13700

Conflict of Interest: The authors declare that the research was conducted in the absence of any commercial or financial relationships that could be construed as a potential conflict of interest.

Copyright ( $\odot 2021$ Boyer, Jandet and Burr. This is an open-access article distributed under the terms of the Creative Commons Attribution License (CC BY). The use, distribution or reproduction in other forums is permitted, provided the original author(s) and the copyright owner(s) are credited and that the original publication in this journal is cited, in accordance with accepted academic practice. No use, distribution or reproduction is permitted which does not comply with these terms. 